\title{
Examining the Nutrient Exchange in All Incubation Periods in Chukar Partridges
}

\author{
A. Kizilaslan, U.G. Simsek
}

10.18805/ag.DF-380

\begin{abstract}
Background: This study was conducted to examine the development of the embryo during incubation and the composition, amount and consumption of the egg nutrients among Chukars (Alectoris chukar).

Methods: A total of 1210 eggs were carefully separated into their components (albumen, yolk, shell, amniotic-allantoic fluid and embryo) on day 0 (fresh), in the first (day 7), second (day 14) and third (day 21) weeks of incubation and on the hatching date. The moisture, crude protein, crude fat, carbohydrate, crude ash and energy level were determined in egg components.

Result: The albumen, yolk, shell, fluid and embryo rates were calculated to be $53.62,34.84,11.53,0.0$ and $0.0 \%$ in fresh egg, 16.74 , $33.49,16.22,31.76$ and $2.06 \%$ in the first week of incubation, $15.65,28.32,15.58,23.35$ and $17.10 \%$ in the second week of incubation and $0.0,23.33,19.38,0.0$ and $57.29 \%$ in the third week of incubation, respectively. The hatching weight of the chick was $16.16 \mathrm{~g}$. The nutrients of the yolk, albumen, fluid and shell proportionally varied significantly in different periods of incubation. According to the nutrient changes calculated based on the weight differences of egg components, carbohydrates were mostly used for nutrients during incubation. It was found that even though the nutrients in all the egg components were used in the different periods of incubation, egg yolk was an important source for the embryo throughout the incubation period.
\end{abstract}

Key words: Egg nutrients, Embryo development, Incubation, Nutrient change, Partridge.

\section{INTRODUCTION}

The urbanization increasing together with the rapidly increasing population in the developing countries has influenced the natural areas and wildlife and narrowed the habitats of wild animals. As the meat of game birds has different flavors and aromas, illegal hunting activities, misuse of agricultural patent medicine and the use of agricultural chemicals are other factors decreasing the populations of these animals (Gruychev, 2016). When considering these factors, special techniques and measures are used to maintain the continuity of wildlife. The primary one among these measures is to release wild animals back into nature after raising them under intensive or semi-intensive conditions. Chukar (Alectoris chukar) is the partridge species that has the widest spreading area and is intensively produced at most in Turkey. As the natural habitat of Chukar partridges is rocky and cliff lands and they prefer the regions without heavy rains, they have found a wide-spreading area in Anatolia (Yamak, 2015). In Turkey, the state farms perform the intensive breeding of partridges and released them into nature. Improving the performance of the partridges, their adaptation to nature, determination of their behavior characteristics, egg quality characteristics, incubation properties, care and, feeding are primary interests for the intensive breeding of partridges (Habibi et al., 2019; Simsek et al., 2020). Knowing the metabolic activities of the embryo developing in an egg is important to perform high-quality and high-performance breeding. Unlike mammals, the nutritional composition of an egg affects significantly the incubation performance and chick quality in poultry. Although the nutrient composition of an egg has been determined in
Department of Animal Science, Faculty of Veterinary Medicine, Firat University, Elazig-23119, Turkey.

Corresponding Author: U.G. Simsek, Department of Animal Science, Faculty of Veterinary Medicine, Firat University, Elazig23119, Turkey. Email: gsimsek@firat.edu.tr

How to cite this article: Kizilaslan, A. and Simsek, U.G. (2021). Examining the Nutrient Exchange in All Incubation Periods in Chukar Partridges. Agricultural Science Digest. DOI: 10.18805/ag.DF-380. Submitted: 17-07-2021 Accepted: 26-10-2021 Online: 09-11-2021

the studies (Song et al., 2000), the limited number of studies have endeavored to reveal the use mechanisms of these nutrients which are not known exactly (Rehault-Godbert et al., 2014; Van Der Wagt et al., 2020). In the eggs of partridges, which weigh approximately 16-25 g (Alkan et al., 2015; Kirikçi et al., 2018), 33.90\% of the egg weight is the yolk, $57.40 \%$ is albumen and $8.70 \%$ is eggshell. The partridge's egg contains moisture of $74.50 \%$, crude protein of $12.60 \%$, crude fat of $11.10 \%$ and crude ash of $1.02 \%$. Albumen contains water of $87.85 \%$, crude protein of $10.15 \%$, crude fat of $0.12 \%$ and crude ash of $0.82 \% .50 .37 \%$ of egg yolk is water, $15.12 \%$ is crude protein, $32.94 \%$ is crude fat and $1.57 \%$ is crude ash (Song et al., 2000). Ovalbumin is $54 \%$ of the protein in albumen. Additionally, another protein with the highest rate of albumen is conalbumin (ovotransferrin). The other proteins in albumen are avidin, ovomucoid, lysozyme and ovoflavoprotein. The proteins in the yolk have mostly a lipoprotein structure. $65 \%$ of the cholesterol in yolk is composed of very-low-density lipoprotein (VLDL). The other yolk proteins are vitellogenin and phosvitin (Zambrowicz et 
al., 2014). It forms the energy needed to synthesize the proteins, which are the building material of the embryo in the incubation period by using carbohydrates of low amounts in the egg. Previous studies determined that as the incubation period progressed, the proteins and fatty acids in eggs are used as a source of energy (Uni et al., 2012; Van Der Wagt et al., 2020). The vitamins and minerals in the structure of the egg play a key role in embryonic development. The mineral matters used in embryonic nutrition are obtained from albumen, shell and yolk. The most important vitamin and mineral source of the embryo is egg yolk (Bauer et al., 2013; Nasir and Peeble, 2018). These nutrients in the egg transmit to the embryo by the vitelline membrane and the veins during incubation. This veining system necessary for embryonic development is separated into parts. The first of these systems is the vitelline veins meeting the nutrient need in the development of the embryo and the other is the allantoic veins providing the removal of the residues of these nutrients and the breathing (Bauer et al., 2013; Nasir and Peeble, 2018). Recent studies are revealing that the embryo consumes orally the nutrients in the egg (Moran, 2007).

Especially in the recent periods in which the studies about in ovo-feeding have increased (Khalil et al., 2021; Matuszewski et al., 2021), accordingly, it is important to know which nutrient is used by the embryo and at which stage of incubation. When the studies on this subject are examined, it is seen that the researches generally focus on egg yolk. Unlike these studies, the present study, it was aimed to examine the changes in the amount of all egg components and the nutrient changes in these components during the incubation period.

\section{MATERIALS AND METHODS Ethical statement}

For the study, approvals were obtained from Firat University Animal Experiments Local Ethics Committee (FÜHADYEK: 13.07.2016 and 132/2016/80) and the Ministry of Agriculture and Forestry General Directorate of Nature Conservation and National Parks (29.06.2016 and 135291).

\section{Experimental design}

The egg material of the study was obtained from the Chukar Partridge (Alectoris chukar) Breeding Station affiliated with Malatya Provincial Branch Office of $15^{\text {th }}$ Regional Directorate of Ministry of Agriculture and Forestry. In the enterprise, maternal Chukars are reared in special wire cages intensively. In the study, the eggs obtained from the 1-yearold Chukars between March and April were used. The female: male ratio was arranged as 2:1 in Chukars. For feeding of stock material, the feed prepared by Nutrient Requirements of Poultry Standards was given ad libitum (Table 1). All eggs were stored in the storage unit of the enterprise at $16^{\circ} \mathrm{C}$ and under the moisture of $70 \%$ for 3 days (Çimuka Egg Storage Cabinet, Turkey). Afterward, they were weighed and the egg weights were written on the eggs using a non-erasable pen. A total of 100 eggs (fresh) were separated and the remaining 1110 eggs were placed in the incubators (Çimuka T1600S, Turkey) in the hatchery of the enterprise. The eggs were incubated at $37.5^{\circ} \mathrm{C}$ and with the moisture of $60 \%$ in the incubation unit and at $37.2^{\circ} \mathrm{C}$ with the moisture of $70 \%$ in the hatching unit. The weighted average of the eggs for each period (days $0,7,14,21$ and 24) was arranged as about $22.50 \mathrm{~g}$. These eggs were carefully separated into the yolk, albumen and shell parts. They were weighed and sampled into $50 \mathrm{ml}$ falcon tubes. A total of 236 eggs were used to prepare the samples of day 7 of incubation. The eggs were weighed and their weight changes were determined, embryonic membranes were carefully opened from the part including the air space and the amniotic-allantoic fluid, albumen, embryo and yolk were separated respectively by being aspirated using a thick injector. The eggshell was cleaned without leaving any residue and then weighed and put into falcon tubes. After the separated parts were weighed, they were placed into falcon tubes. In the second week of the incubation, 332 eggs were used to examine the egg characteristics. After the eggs were weighed and their weight changes were examined, their fluid, embryo, yolk, albumen and shell were separated. The weighed parts were placed into falcon tubes. A total of 288 eggs were examined in the third week of the incubation. As the fluid and albumen remained in trace amounts in the egg, these parts were not collected. The shells, yolks and embryos were weighed and the shells and yolks were transferred to falcon tubes. The chicks hatching on day 24 of the incubation were weighed and separated. The shells were weighed and transferred into falcon tubes. 254 eggs were examined for this period. Infertile eggs, dead embryos and contaminated eggs were separated and excluded from the experiment. A different number of eggs were broken in each period to provide an adequate sampling. Ten samples were prepared for each content as 10 repetitions in examined periods. The samples were kept at $-20^{\circ} \mathrm{C}$ until the analysis. On the analysis day, the samples solubilized at $+4^{\circ} \mathrm{C}$ were homogenized and analyzed. Moisture, crude protein, crude fat, crude ash, carbohydrate and energy levels were examined in the amniotic-allantoic fluid, albumen, yolk and shell parts of the egg. The analyses were performed in an accredited laboratory, Nano-Lab Food and Feed Analysis Laboratory. The real nutrient amount $(\mathrm{g}$ ) of each period (fresh eggs, first, second and third weeks) was determined using the proportional values (\%) of the moisture and nutrient data of that period and the weight changes in each parameter were calculated and were presented proportionally.

The following formulae were used for the data collection; Moisture or nutrient amounts $=$ Proportional value (moisture or nutrient) $\% \times$ The weight of the examined parameter in the examined period (shell, yolk, albumen or fluid, g) / 100. Changing, $\%=[($ Amount in the examined period $(g)-$ Amount in the fresh egg $(g) /$ Amount in the fresh egg $(g)] \times 100$.

\section{Chemical analysis}

The moisture, crude protein, crude fat and crude ash in albumen, yolk, fluid and shell of eggs were performed based 
on the methods stated in AOAC, ISO 1871 and NMKL No:160 (AOAC, 2000). The number of carbohydrates was determined by calculation (Anonymous, 2002).

\section{Statistical analysis}

In the study, the actual and proportional values of egg components and their composition in fresh eggs and different periods of incubation were presented as mean \pm standard error. One-way analysis of variance (ANOVA) was used in the comparison of the data of the different periods of incubation and the egg composition and the Tukey HSD test was used in the advanced analyses. The analyses were performed using SPSS 21.0 software (SPSS Inc., Chicago, IL, USA). The value of $P \leq 0.05$ was found to be statistically significant.

\section{RESULTS AND DISCUSSION}

Table 2 shows the albumen, yolk, shell, fluid and embryo rates in the different periods of incubation in the eggs of Chukar partridges. These rates were determined to be 53.62, $34.84,11.53,0.0$ and $0.0 \%$ on the day 0 (fresh egg), 16.47 ,

Table 1: Composition of the feed used for Chukar partridges.

\begin{tabular}{lc}
\hline Raw material & Amount (\%) \\
\hline Moisture & 10.29 \\
Crude protein & 17.74 \\
Crude oil & 4.76 \\
Crude ash & 10.71 \\
Carbohydrate & 56.5 \\
Metabolic energy & $2700 \mathrm{kcal} / \mathrm{kg}$ \\
\hline
\end{tabular}

Vitamin A (IU/Kg) 10.000, E671 Vitamin D3 (IU/Kg) 2.500, 3a700
Vitamin E (mg/kg) 20, Calcium (\%) 3.80, phosphorus (\%) 0.70 , Sodium (\%) 0.20, Lysine (\%) 0.80, Methionine (\%) 0.45, Mn (E5, Manganese Oxide) (mg/kg) 100, Zn (E6, Zinc Oxide) (mg/kg) 60, Se (E8, Sodium Selenite) $(\mathrm{mg} / \mathrm{kg})$ 0.20, Cu (E4, Copper Sulfate) $(\mathrm{mg} / \mathrm{kg}) 5.00$
$33.49,16.22,31.76$ and $2.06 \%$ on day $7,15.65,28.32,15.58$, 23.35 and $17.10 \%$ on day 14 and $0.0,23.33,19.38,0.0$ and $57.29 \%$ on day 21 of incubation, respectively. The shell ratio on the hatching day $\left(24^{\text {th }}\right)$ was $8.41 \%$ and the mean chick weight was $16.16 \mathrm{~g}$ (\%72.04). The proportional values of the fresh egg components are compatible with the other studies (Song et al., 2000; Alkan et al., 2015; Kirikçi et al., 2018). However, no previous information was available on the changes in egg components during incubation. In the following periods of incubation, the decrease in albumen and fluid was remarkable. Moran (2007) states that the embryo uses albumen and yolk through the vitelline membrane for 14 days of its development and consumes albumen and amniotic-allantoic fluid mixture by oral route after day 14 . Similarly, it was determined in the present study that both egg components were finished on day 21 of incubation. The egg weight change was similar in the examined periods of incubation ( $3-4 \%$ ) and the growth rate of the embryo varied during incubation and increased significantly towards the end of incubation mostly between days 14 and 21 (Table 2 ).

Table 3 shows the proportional values of the nutrient components of the egg in different periods of incubation. When examined weekly, the moisture content of yolk increased in the first week and then decreased. It could be related that the increase in the yolk's moisture level in the first week was associated with the fluid and electrolyte flow from the fluid and albumen due to the osmolarity difference between the egg components (Uni et al., 2012). Another reason for the increase in the moisture level of the yolk is thought to be the lipids hydrolyzed during the use of yolk through a vitelline membrane (Maatjens et al., 2014; Sheng, 2014). The crude protein content of yolk decreased until the last week of incubation. It increased significantly in the last week. The crude fat content of yolk increased significantly in the third week and decreased in the last week. While its carbohydrate level increased in the last week, its

Table 2: Egg characteristics in different periods of incubation in Chukar partridges.

\begin{tabular}{lccccc}
\hline Traits & Fresh (Day 0) & Day 7 & Day 14 & Day 21 & Day 24 \\
\hline Initial egg weight (EW), g & $22.50 \pm 0.06$ & $22.50 \pm 0.04$ & $22.50 \pm 0.03$ & $22.50 \pm 0.02$ & $22.43 \pm 0.02$ \\
EW, g & - & $21.69 \pm 0.04$ & $21.05 \pm 0.04$ & $20.16 \pm 0.04$ & - \\
Change of EW, g & - & $0.81 \pm 0.03$ & $1.45 \pm 0.02$ & $2.34 \pm 0.03$ & - \\
EW change, \% & - & $3.64 \pm 0.15$ & $6.50 \pm 0.10$ & $10.46 \pm 0.15$ & - \\
Albumen weight, g & $12.06 \pm 0.05$ & $3.57 \pm 0.07$ & $3.29 \pm 0.08$ & - & - \\
Yolk weight, g & $7.84 \pm 0.05$ & $7.26 \pm 0.11$ & $5.96 \pm 0.09$ & $4.70 \pm 0.05$ & - \\
Amniotic-allantoic weight, g & - & $6.88 \pm 0.07$ & $4.91 \pm 0.08$ & - & - \\
Embryo weight, g & - & $0.45 \pm \leq 0.0$ & $3.60 \pm 0.02$ & $11.54 \pm 0.04$ & $16.16 \pm 0.03$ \\
Shell weight, g & $2.59 \pm 0.01$ & $3.52 \pm 0.05$ & $3.28 \pm 0.03$ & $3.90 \pm 0.03$ & $1.88 \pm 0.02$ \\
Albumen ratio, \% & $53.62 \pm 0.19$ & $16.47 \pm 0.31$ & $15.65 \pm 0.38$ & - & - \\
Yolk ratio, \% & $34.84 \pm 0.18$ & $33.49 \pm 0.55$ & $28.32 \pm 0.47$ & $23.33 \pm 0.24$ & - \\
Shell ratio, \% & $11.53 \pm 0.07$ & $16.22 \pm 0.25$ & $15.58 \pm 0.18$ & $19.38 \pm 0.17$ & $8.41 \pm 0.08$ \\
Amniotic - allantoic ratio, \% & - & $31.76 \pm 0.33$ & $23.35 \pm 0.37$ & - & - \\
Embryo ratio, \% & - & $2.06 \pm 0.04$ & $17.10 \pm 0.13$ & $57.29 \pm 0.21$ & - \\
\hline
\end{tabular}

Proportional values were calculated based on $100 \mathrm{~g}$ egg weight. The data are given as mean \pm standard error. 
Examining the Nutrient Exchange in All Incubation Periods in Chukar Partridges

Table 3: Nutritional composition of egg in different periods of incubation in Chukar partridges.

\begin{tabular}{|c|c|c|c|c|c|c|}
\hline Days & Moisture (\%) & Crude Protein (\%) & Crude Fat (\%) & Carbohydrate (\%) & Crude Ash (\%) & Energy (Kcal) \\
\hline \multicolumn{7}{|l|}{ Yolk } \\
\hline Fresh (day 0) & $45.14 \pm 0.87^{c}$ & $18.61 \pm 0.32^{b}$ & $30.86 \pm 0.78^{b}$ & $3.02 \pm 1.16^{\mathrm{ab}}$ & $2.35 \pm 0.11^{\mathrm{a}}$ & $364.34 \pm 5.95^{a}$ \\
\hline Day 7 & $53.60 \pm 0.69^{a}$ & $16.28 \pm 0.42^{c}$ & $25.90 \pm 0.78^{c}$ & $2.11 \pm 0.74^{b}$ & $2.09 \pm 0.07^{\mathrm{ab}}$ & $306.70 \pm 5.87^{b}$ \\
\hline Day 14 & $45.86 \pm 0.42^{\mathrm{bc}}$ & $16.58 \pm 0.57^{c}$ & $34.44 \pm 0.38^{\mathrm{a}}$ & $0.67 \pm 0.14^{\mathrm{b}}$ & $2.43 \pm 0.18^{a}$ & $379.04 \pm 3.04^{\mathrm{a}}$ \\
\hline Day 21 & $48.58 \pm 0.91^{b}$ & $21.85 \pm 0.39^{a}$ & $21.81 \pm 1.23^{d}$ & $6.00 \pm 1.07^{\mathrm{a}}$ & $1.75 \pm 0.13^{b}$ & $307.71 \pm 7.96^{b}$ \\
\hline \multicolumn{7}{|l|}{ Albumen } \\
\hline Fresh (day 0) & $88.34 \pm 0.17^{a}$ & $9.56 \pm 0.16^{b}$ & $0.25 \pm 0.02^{b}$ & $1.10 \pm 0.10^{\mathrm{a}}$ & $0.72 \pm 0.02^{b}$ & $45.00 \pm 0.86^{c}$ \\
\hline Day 7 & $62.94 \pm 0.44^{b}$ & $33.54 \pm 0.46^{a}$ & $1.69 \pm 0.21^{\mathrm{a}}$ & $0.82 \pm 0.14^{\mathrm{a}}$ & $0.99 \pm 0.04^{a}$ & $152.70 \pm 1.60^{\mathrm{a}}$ \\
\hline Day 14 & $63.22 \pm 0.36^{\mathrm{b}}$ & $34.22 \pm 0.47^{\mathrm{a}}$ & $0.66 \pm 0.18^{b}$ & $0.82 \pm 0.16^{a}$ & $1.05 \pm 0.06^{\mathrm{a}}$ & $146.19 \pm 1.86^{b}$ \\
\hline \multicolumn{7}{|c|}{ Amniotic-allantoic } \\
\hline Day 7 & $90.53 \pm 0.87^{a}$ & $2.15 \pm 0.40^{\mathrm{b}}$ & $5.57 \pm 0.42^{\mathrm{a}}$ & $0.74 \pm 0.14^{a}$ & $0.99 \pm 0.08^{b}$ & $61.78 \pm 5.34^{a}$ \\
\hline Day 14 & $92.09 \pm 0.34^{a}$ & $5.48 \pm 0.45^{\mathrm{a}}$ & $0.70 \pm 0.07^{b}$ & $0.61 \pm 0.23^{a}$ & $1.10 \pm 0.05^{\mathrm{a}}$ & $30.72 \pm .26^{b}$ \\
\hline \multicolumn{7}{|l|}{ Egg shell } \\
\hline Fresh (day 0) & - & - & - & - & $89.83 \pm 0.78^{a}$ & - \\
\hline Day 7 & - & - & - & - & $86.97 \pm 0.67^{b}$ & - \\
\hline Day 14 & - & - & - & - & $89.94 \pm 0.41^{a}$ & - \\
\hline Day 21 & - & - & - & - & $89.13 \pm 0.16^{\mathrm{a}}$ & - \\
\hline Day 24 & - & - & - & - & $88.58 \pm 0.26^{\mathrm{ab}}$ & - \\
\hline
\end{tabular}

The data are given as mean \pm standard error. $a, b, c, d$ - the difference between mean values represented by letters in the same column is significant $(P \leq 0.05)$.

crude ash content decreased in egg yolk. The energy level of the yolk was calculated to be high in the first and third weeks and low in the second and the fourth weeks. Embryo growing rapidly during incubation that used all the nutrients in egg yolk. The fluctuation was observed in the crude protein and fat contents and the carbohydrate level increased significantly towards the end of incubation. The reason for the fluctuations in the crude protein and fat rates of the yolk was the proteins coming from the albumen and the fluid. The previous studies revealed that it was also caused by the proteins and lipids releasing as a result of the degradation of the yolk sac (Yadgary et al., 2010). Uni et al. (2012) determined that the lipid consumption of yolk increased towards the end of incubation, which was similar to the results of this study. It was determined that the significant increase of the carbohydrates in yolk was associated significantly with carbohydrate synthesis in the egg performed to provide the energy needed by the embryo while being prepared for hatching day. Yadgary and Uni (2012) stated that gene expression levels of glycogen synthase, glycogen phosphorylase, gluconeogenic enzymes fructose 1,6-bisphosphatase, phosphoenolpyruvate carboxykinase and glucose 6-phosphatase increased significantly in the liver of embryo in this period. Table 3 also shows the nutrient content of albumen in the first three measurements. The moisture content of albumen decreased significantly from the first measurement; whereas, the crude protein and ash content increased. The carbohydrate level did not change. The crude fat and energy level increased in the first week and decreased again in the third week. The moisture and carbohydrate contents did not change in the fluid that can be collected in the first and the second weeks of incubation. While crude protein and ash content of the fluid increased, its crude fat and energy level decreased. The crude ash content of the shell decreased significantly in the first week and the differences in the crude ash content were not statistically significant in the following weeks.

Table 4 shows the nutritional changes of the egg components in the different periods of incubation. The carbohydrate content of yolk decreased between days 0 and 7 and its moisture content increased. The change of the other nutrients was similar. The carbohydrates of egg yolk were consumed mostly between days 8 and 14, its crude fat and energy level increased and the other nutrients reduced gradually. The carbohydrate content of yolk between days 15 and 21 increased significantly, its protein content increased and the reducing change of the other nutrients was similar. It was determined that all the nutrients in yolk were consumed gradually between days 0 and 21 . While the highest change was observed in the carbohydrate content, the lowest change was observed in the energy level and the decreases in the moisture, crude protein, fat and ash contents were statistically similar. The energy, crude fat and crude protein contents of albumen increased significantly between days 0 and 7 , respectively and the moisture, carbohydrate and crude ash contents decreased similarly. The crude fat content of albumen decreased mostly between days 8 and 14, which was followed by moisture, ash, carbohydrate, protein and energy. The energy and crude protein contents of albumen increased significantly between days 0 and 14 and the moisture, carbohydrate, crude ash and fat contents decreased. The crude protein and ash contents of the fluid increased between days 8 and 14 and the crude fat, crude ash, energy and moisture 
Examining the Nutrient Exchange in All Incubation Periods in Chukar Partridges

Table 4: Nutritional changes in Chukar partridges in different periods of incubation.

\begin{tabular}{|c|c|c|c|c|c|c|}
\hline Days & Moisture (\%) & Protein (\%) & Fat $(\%)$ & Carbohydrate (\%) & Ash (\%) & Energy (Kcal) \\
\hline \multicolumn{7}{|l|}{ Yolk } \\
\hline Days $0-7$ & $10.25 \pm 3.30^{\mathrm{a}, \mathrm{A}}$ & $-18.93 \pm 2.00^{\mathrm{b}, \mathrm{B}}$ & $-21.90 \pm 3.70^{\mathrm{b}, \mathrm{B}}$ & $-59.39 \pm 12.42^{b, c}$ & $-16.71 \pm 4.07^{\mathrm{ab}, \mathrm{B}}$ & $-15.61 \pm 2.80^{\mathrm{b}, \mathrm{B}}$ \\
\hline Days 8-14 & $-29.75 \pm 0.29^{c, B C}$ & $-16.43 \pm 1.47^{\mathrm{b}, \mathrm{ABC}}$ & $9.66 \pm 3.44^{\mathrm{a}, \mathrm{AB}}$ & $-78.69 \pm 5.25^{b, c}$ & $-3.05 \pm 9.94^{\mathrm{a}, \mathrm{ABC}}$ & $23.75 \pm 1.88^{\mathrm{a}, \mathrm{A}}$ \\
\hline Days $15-21$ & $-16.46 \pm 1.36^{\mathrm{b}, \mathrm{B}}$ & $4.46 \pm 3.60^{\mathrm{a}, \mathrm{B}}$ & $-50.12 \pm 2.61^{\mathrm{C}, \mathrm{B}}$ & $236.64 \pm 7.78^{\mathrm{a}, \mathrm{A}}$ & $-40.64 \pm 8.02^{\mathrm{b}, \mathrm{B}}$ & $-18.83 \pm 1.89^{b, B}$ \\
\hline Days $0-14$ & $-22.76 \pm 2.06^{\mathrm{B}}$ & $-32.27 \pm 1.84^{\mathrm{B}}$ & $-21.90 \pm 3.70^{\mathrm{B}}$ & $-83.27 \pm 7.88^{c}$ & $-21.39 \pm 6.12^{\mathrm{B}}$ & $4.03 \pm 1.88^{\mathrm{A}}$ \\
\hline Days $0-21$ & $-35.48 \pm 1.48^{\mathrm{AB}}$ & $-29.61 \pm 1.52^{\mathrm{AB}}$ & $-57.35 \pm 2.93^{\mathrm{AB}}$ & $-62.81 \pm 6.16^{\mathrm{B}}$ & $-55.35 \pm 2.82^{\mathrm{AB}}$ & $-15.42 \pm 2.59^{A}$ \\
\hline \multicolumn{7}{|l|}{ Albumen } \\
\hline Days $0-7$ & $-78.80 \pm 0.13^{\mathrm{a}, \mathrm{D}}$ & $3.02 \pm 2.13^{b, C}$ & $91.98 \pm 13.93^{a, b}$ & $-60.81 \pm 17.13^{b, D}$ & $-56.55 \pm 4.46^{\mathrm{b}, \mathrm{D}}$ & $236.52 \pm 6.26^{\mathrm{a}, \mathrm{A}}$ \\
\hline Days 8-14 & $-7.93 \pm 0.98^{\mathrm{b}, \mathrm{B}}$ & $-5.40 \pm 1.64^{\mathrm{a}, \mathrm{B}}$ & $-61.15 \pm 8.18^{b, c}$ & $-6.43 \pm 2.37^{\mathrm{a}, \mathrm{B}}$ & $-6.45 \pm 2.07^{\mathrm{a}, \mathrm{B}}$ & $-3.29 \pm 1.03^{\mathrm{b}, \mathrm{A}}$ \\
\hline Days $0-14$ & $-80.47 \pm 0.11^{c}$ & $2.35 \pm 2.84^{\mathrm{B}}$ & $-27.98 \pm 8.75^{\mathrm{BC}}$ & $-79.66 \pm 6.52^{\mathrm{C}}$ & $-60.21 \pm 2.50^{C}$ & $219.15 \pm 6.62^{A}$ \\
\hline \multicolumn{7}{|c|}{ Amniotic-allantoic } \\
\hline Days 8-14 & $-27.37 \pm 0.72^{C}$ & $115.57 \pm 13.05^{A}$ & $-90.74 \pm 1.12^{\mathrm{C}}$ & $-65.40 \pm 4.48^{\mathrm{C}}$ & $18.77 \pm 5.61^{\mathrm{B}}$ & $-48.42 \pm 4.72^{\mathrm{C}}$ \\
\hline \multicolumn{7}{|l|}{ Egg shell } \\
\hline Days $0-7$ & - & - & - & - & $31.65 \pm 1.31^{\mathrm{a}}$ & - \\
\hline Days 8-14 & - & - & - & - & $-3.59 \pm 0.86^{c}$ & - \\
\hline Days $15-21$ & - & - & - & - & $17.06 \pm 0.95^{b}$ & - \\
\hline Days $22-24$ & - & - & - & - & $-51.21 \pm 0.87^{d}$ & - \\
\hline Days $0-14$ & - & - & - & - & $26.79 \pm 1.55$ & - \\
\hline Days $0-21$ & - & - & - & - & $49.40 \pm 1.42$ & - \\
\hline Days $0-24$ & - & - & - & - & $-60.03 \pm 1.14$ & - \\
\hline
\end{tabular}

The data are given as mean \pm standard error; $a, b, c, d$ - the difference between mean values represented by letters in the same column is significant $(P \leq 0.05)$; $A, B, C$ - the difference between mean values represented by letters in the same row is significant $(P \leq 0.05)$.

contents decreased significantly. The crude ash change in eggshell on the days 0 and 24 were found to be $-60.03 \pm$ $1.14 \%$. Similarly, Yair and Uni (2011) stated that yolk was rich in $\mathrm{Mn}, \mathrm{P}, \mathrm{Fe}, \mathrm{Ca}, \mathrm{Cu}$ and $\mathrm{Zn}$ and the mineral consumption of yolk was low at the beginning and increased mostly between days 11 and 17 of incubation and then decreased again. The crude ash consumption of yolk was determined to be the highest on days 15 and 21 of incubation in the present study. The studies generally focused on the nutrient composition of yolk and a limited number of studies on the nutrient change in the other parts of the egg were found. When the nutrient change of albumen in the various periods of incubation was examined (Table 4), the moisture level of albumen decreased significantly in the first week and the concentration relatively continued in the other period. The crude protein and fat level of albumen increased in the first week, then decreased in the second week and had a value less than the initial amount. It was considered that the increase in the protein and fat amount of albumen in the first week of incubation was caused by the demand of these matters to pass to the less concentrated environment from the high concentrated environment and the difference in the osmotic pressure (Uni et al., 2012). The fact that the color of albumen became yellowish at the end of the first week may be an important indicator of the passage of some matters caused especially by yolk. The ash and carbohydrate level of albumen decreased continuously and proportionally as of the beginning. The energy of albumen increased in the first week and was relatively lower in the second week. This increase in the energy of albumen was caused by the increase of the crude protein and fat content of albumen in the first week. The fact that the ash and carbohydrate amount of albumen continuously decreased proportionally corresponds to the information that albumen is an important source of $\mathrm{Na}, \mathrm{K}$ and carbohydrate of the embryo (Uni et al., 2012). In the examination of fluid, the moisture content of the fluid decreased on days 8 and 14 . The crude protein content of the fluid increased on days 8 and 14 . The crude fat, carbohydrate and energy rates of the fluid decreased among the examined periods. The crude protein and ash increase in the fluid is considered to indicate that the embryo starts to form uric acid crystals in the urinary system in this period. It was thought that the protein amount in the fluid increases as it is known that uric acid crystals are present in association with urate monosodium salt or proteins and the protein amount was found by calculating the $\mathrm{N}$ number in the present study (Stower and Bertocchini, 2017). The fact that the crude ash amount in the eggshell was significantly lower than the initial value corresponds to the information that it is used as a source of phosphor, sodium, iron and manganese and three is high amounts of calcium, magnesium and sulfur required for feeding of the embryo (Uni et al., 2012). It was considered that the increase in the ash level of the shell between the days 0-14 and 0-21 was because the chorio-allantoic membrane covers the inner membrane of the eggshell and it becomes thick. The crude ash analyses of eggshells were performed in the membranous eggshell. 
Examining the Nutrient Exchange in All Incubation Periods in Chukar Partridges

\section{CONCLUSION}

Consequently, it was determined that the embryo used all egg nutritional components in varying proportions during development, but egg yolk was an important source for the embryo. The embryo has grown very rapidly in the second stage of incubation and there is an important carbohydrate cycle within the egg during hatching.

\section{ACKNOWLEDGEMENT}

We thank Firat University Scientific Research Projects Unit for supporting this research financially (VF.17.19) and the Ministry of Agriculture and Forestry Malatya Province Directorate of Nature Conservation and National Parks.

\section{Conflict of interest}

The authors declared that there is no conflict of interest

\section{REFERENCES}

A.O.A.C. (2000). Official Methods of Analysis. $17^{\text {th }}$ Edition, Washington DC Association of Official Agricultural Chemist.

Alkan, S., Galiç, A., Karsli, T., Karabağ, K. (2015). Effects of egg weight on egg quality traits in partridge (Alectoris chukar). Journal of Applied Animal Research. 43: 450-456.

Anonymous (2002). Food Energy-methods of Analysis and Conversion Factors. FAO Food and Nutrition Paper 77. ISSN 02544725. Report of a Technical Workshop. Rome.

Bauer, R., Plieschnig, J.A., Finkes, T., Riegler, B., Hermann, M., Schneider, W.J. (2013). The developing chicken yolk sac acquires nutrient transport competence by an orchestrated differentiation process of its endodermal epithelial cells. Journal of Biological Chemistry. 288: 1088-1098.

Gruychev, G. (2016). Declining populations of Chukar partridge (Alectoris chukar) in Bulgaria. Turkish Journal of Zoology. 40: 818-823.

Habibi, H., Ghahtan, N., Brooks, D.M. (2019). Effect of sex ratio, storage time and temperature on hatching rate, fertility and embryonic mortality in Chukar partridge (Alectoris chukar). Animal Reproduction Science. 203: 68-74.

Khalil, M.H., Hassan M.I., Elghalid, O.A., Hassan, S.S. (2021). The effect of in ovo injection of bee venom on hatchability and some immunological parameters of Alexandria chicks' strain at hatch. Egyptian Poultry Science Journal. 41: 113.

Kirikçi, K., Çam, M., Başer, E., Akbulut, N.K., Bilgiç, M.A. (2018). Effects of egg weight on hatchability characteristics in Chukar partridges. Journal of Bahri Dagdas Animal Research. 7: 1-6.

Maatjens, C.M., Reijrink, I.A.M., Van Den Anker, I., Molenaar, R., Van Der Pol, C.W., Kemp, B., Van Den Brand, H. (2014). Temperature and $\mathrm{CO}_{2}$ during the hatching phase. I. Effects on chick quality and organ development. Poultry Science. 93: 645-654.
Matuszewski, A., Łukasiewicz, M., Niemiec, J. (2021). Calcium carbonate nanoparticles-toxicity and effect of in ovo inoculation on chicken embryo development, broiler performance and bone status. Animals. 11: 932.

Moran, J.E.T. (2007). Nutrition of the developing embryo and hatchling. Poultry Science 86: 1043-1049.

Nasir, Z., Peeble, E.D. (2018). Symposium: avian embryo nutrition and incubation. Poultry Science. 97: 2994-2995.

Reihault-Godbert, S., Mann, K., Bourin, M. (2014). Effect of embryonic development on the chicken egg yolk plasma proteome after 12 days of incubation. Journal of Agricultural and Food Chemistry. 62: 2531-2540.

Sheng, G. (2014). Day 1 chick development. Developmental Dynamics. 243: 357-67.

Simsek, U.G., Ciftci, M., Yaman, M., Ozcelik, M., Baykalır, Y., Kızılaslan, A., Bayrakdar, A., Cambay, Z., Yakut, S., Erisir, Z. (2020). Effects of light color on growth performance, histomorphometric features of small intestine and some blood parameters in Chukar partridges (Alectoris chukar). Kafkas Universitesi Veteriner Fakultesi Dergisi. 26: 3339.

Song, K.T., Choi, S.H., Oh, H.R. (2000). A comparison of egg quality of pheasant, chukar, quail and guinea fowl. AsianAustralasian Journal of Animal Sciences. 13: 986-990.

Stower, M.J., Bertocchini, F. (2017). The evolution of amniote gastrulation: The blastopore primitive streak transition. Wiley Interdisciplinary Reviews: Developmental Biology. 6: 262.

Uni, Z., Yadgary, L., Yair, R. (2012). Nutritional limitations during poultry embryonic development. Journal of Applied Poultry Research. 21: 175-184.

Van Der Wagt, I., Jong, I.C., Mitchell, M.A. (2020). A review on yolk sac utilization in poultry. Poultry Science. 99: 21622175.

Yadgary, L., Cahaner, A., Kedar, O. (2010). Yolk sac nutrient composition and fat uptake in late-term embryos in eggs from young and old broiler breeder hens. Poultry Science. 89: 2441-2452.

Yadgary, L., Uni, Z. (2012). Yolk sac carbohydrate levels and gene expression of key gluconeogenic and glycogenic enzymes, as compared to the liver, during chick embryonic development. Poultry Science. 91: 444-453.

Yair, R., Uni, Z. (2011). Content and uptake of minerals in the yolk of broiler embryos during incubation and effect of nutrient enrichment. Poultry Science. 90: 1523-1531.

Yamak, U.S. (2015). Artificial breeding of wild birds in Turkey: Partridge breeding case. Indian Journal of Animal Research. 49: 258-261.

Zambrowicz, A., Dąbrowska, A., Bobak, L. (2014). Egg yolk proteins and peptides with biological activity. Postepy Higieny I Medycyny Doswiadczalnej. 68: 1524-1529. 